\title{
Titan's Carbon Budget and the Case of the Missing Ethane ${ }^{\dagger}$
}

\author{
Eric H. Wilson*, ${ }^{*, \S}$ and Sushil K. Atreya ${ }^{\S}$ \\ Jet Propulsion Laboratory, 4800 Oak Grove Drive M/S 169-237, Pasadena, California 91109-8099, \\ Department of Atmospheric, Oceanic, and Space Sciences, University of Michigan, \\ Ann Arbor, Michigan 48109-2143
}

Received: June 12, 2009; Revised Manuscript Received: August 26, 2009

\begin{abstract}
The retrieval of data from the Cassini-Huygens mission has revealed much about Titan's atmosphericsurface system and has precipitated more questions. One of these questions involves the lack of large reservoirs of ethane that were predicted by a variety of studies prior to the arrival of the Cassini-Huygens spacecraft. Using an updated and comprehensive photochemical model, we examine the nature of Titan's carbon budget, initiated by the destruction of methane, and the role that ethane condensation plays in this budget. Model results show that $40 \%$ of methane destruction results in ethane formation, with a net production rate of $2.7 \times 10^{9}$ molecules $\mathrm{cm}^{-2} \mathrm{~s}^{-1}$, due primarily to acetylenic catalysis in Titan's stratosphere. This corresponds to a liquid ethane layer of several hundred meters over geologic time. However, episodic methane outgassing, subsurface sequestration, and chemical processing of Titan's surface are likely responsible for the limiting of ethane condensate on Titan's surface to less than $10 \mathrm{~m}$ globally averaged.
\end{abstract}

\section{Introduction}

In Titan's atmosphere, photochemistry of the methane molecule controls the composition of the atmosphere as well as the surface. Methane is photolyzed by ultraviolet radiation and irreversibly converted to larger hydrocarbons, which populate the atmosphere, serve as precursors to Titan's opaque haze layer, and condense out to provide Titan much of its surface material.

The destruction of methane by photolysis in Titan's atmosphere was first demonstrated in pre-Voyager studies by Strobel. ${ }^{1}$ Ground-based observations during the same period provided evidence of $\mathrm{C}_{2}{ }^{-}$hydrocarbons and propane $\left(\mathrm{C}_{3} \mathrm{H}_{8}\right)$ along with haze particles in the atmosphere, ${ }^{2}$ the eventual products of methane photolysis. The formation of these products was confirmed by the flyby of Voyager 1, which demonstrated the existence of simple hydrocarbons and nitriles in addition to haze, ${ }^{3}$ resulting from methane and nitrogen photochemistry.

As photochemical models began to investigate the nature of methane conversion to other hydrocarbons, ${ }^{4,5}$ the idea was proposed that the primary product of methane photolysis would be a substantial ethane ocean. On the basis of the models and Voyager radio occultation observations, ${ }^{6}$ Lunine et al. ${ }^{7}$ suggested that Titan was covered by a kilometer-deep ocean, consisting primarily of ethane, due to the irreversible conversion of methane to ethane through photolytic processes and its subsequent condensation. Until the arrival of Cassini-Huygens, many lakes or a global ocean were predicted to be found on the surface of Titan.

The arrival of the Cassini-Huygens spacecraft at Saturn in 2004 provided a wealth of information about Titan's atmosphere and surface. The observations from the gas chromatograph mass spectrometer (GC/MS $)^{8}$ on the Huygens probe combined with remote sensing of surface features from

\footnotetext{
"Part of the special section "Chemistry: Titan Atmosphere".

* Corresponding author. E-mail: titansat74@yahoo.com.

* Jet Propulsion Laboratory.

${ }^{\S}$ University of Michigan.
}

the visual and infrared mapping spectrometer (VIMS) $)^{9}$ and RADAR $^{10}$ instruments from the Cassini orbiter suggest that a "methalogical" cycle exists on Titan, ${ }^{11,12}$ with methane playing a role on Titan similar to that of water in the hydrological cycle on the Earth. The surface consists of primarily water ice and dark tholin material with the possibility of some condensed hydrocarbons and nitriles. ${ }^{13}$ Furthermore, features that correspond to lakes or seas have been identified on Titan's surface. ${ }^{14}$ In one of these features, a large lakelike region named Ontario Lacus, liquid ethane has been identified. ${ }^{15}$ However, it is evident that no global ocean of ethane exists on Titan.

Previous studies have addressed the question of methane conversion to ethane but have not included the comprehensive neutral and ion chemistry necessary to thoroughly explain Titan's chemical carbon budget. This paper seeks to explore why the past estimates of ethane condensation have not been observed and the implications this absence has on the past and present-day Titan surface-atmosphere system. To address this question, we present an updated comprehensive photochemical model with an eddy diffusion profile adjusted in the context of the recent observations from the Cassini-Huygens mission.

\section{Hydrocarbon Chemistry}

Ethane can be formed from direct photolysis of methane in the upper atmosphere, acetylene-catalyzed photochemistry in the lower atmosphere, and ion chemistry above approximately $700 \mathrm{~km}$ in Titan's atmosphere. The production of all hydrocarbons in Titan's atmosphere commences with the photodissociation of methane (Table 1). Methane absorbs ultraviolet photons shortward of $1450 \AA$, with Lyman $\alpha$ photons accounting for $75 \%$ of methane photoabsorption. ${ }^{16}$ The resulting photodissociation takes place in Titan's upper atmosphere, peaking at about $800 \mathrm{~km}$, the altitude of Lyman 
TABLE 1: Methane Destruction and Ethane Production Rates in Titan's Atmosphere ${ }^{a}$

\begin{tabular}{lccc}
\hline & above $700 \mathrm{~km}$ & below $700 \mathrm{~km}$ & total \\
\hline (1) $\mathrm{CH}_{4}$ photodestruction & $2.5 \times 10^{9}$ & $8.0 \times 10^{7}$ & $2.5 \times 10^{9}$ \\
(2) $\mathrm{CH}_{4}$ photosensitized destruction & $8.8 \times 10^{7}$ & $5.7 \times 10^{9}$ & $5.7 \times 10^{9}$ \\
$\mathrm{CH}_{4}$ chemical destruction ex. 1, 2 & $2.3 \times 10^{9}$ & $2.8 \times 10^{8}$ & $2.6 \times 10^{9}$ \\
$\mathrm{CH}_{4}$ escape & $\mathrm{N} / \mathrm{A}$ & $\mathrm{N} / \mathrm{A}$ & $2.9 \times 10^{9}$ \\
$\mathrm{CH}_{4}$ chemical production & $1.6 \times 10^{8}$ & $8.6 \times 10^{8}$ & $1.0 \times 10^{9}$ \\
$\mathrm{Net} \mathrm{CH}_{4}$ destruction (+ escape) & $4.7 \times 10^{9}$ & $5.2 \times 10^{9}$ & $1.3 \times 10^{10}$ \\
$\mathrm{C}_{2} \mathrm{H}_{6}$ production from 1 & $9.3 \times 10^{7}$ & $3.9 \times 10^{7}$ & $1.3 \times 10^{8}$ \\
$\mathrm{C}_{2} \mathrm{H}_{6}$ production from 2 & $3.4 \times 10^{6}$ & $3.2 \times 10^{9}$ & $3.2 \times 10^{9}$ \\
$\mathrm{C}_{2} \mathrm{H}_{6}$ chemical destruction & $1.1 \times 10^{7}$ & $4.6 \times 10^{8}$ & $4.7 \times 10^{8}$ \\
$\mathrm{Net}_{2} \mathrm{H}_{6}$ production & $8.4 \times 10^{7}$ & $2.7 \times 10^{9}$ & $2.7 \times 10^{9}$
\end{tabular}

${ }^{a}$ All values in molecules $\mathrm{cm}^{-2} \mathrm{~s}^{-1}$, referred to the surface, as follows: total (prod, loss) $=\int(P, L)(z)\left(r^{2} / r_{0}^{2}\right) \mathrm{d} r ; r_{0}=$ Titan radius.

$\alpha$ deposition, at a rate of $2.5 \times 10^{9}$ molecules $\mathrm{cm}^{-2} \mathrm{~s}^{-1}$, as obtained by integrating the curve in Figure 1, referred to the surface.

Methane photolysis can take place through a variety of photodissociation channels, as shown below:

$$
\begin{aligned}
\mathrm{CH}_{4}+h v & \rightarrow \mathrm{CH}_{3}+\mathrm{H} \\
& \rightarrow{ }^{1} \mathrm{CH}_{2}+\mathrm{H}_{2} \\
& \rightarrow{ }^{1} \mathrm{CH}_{2}+2 \mathrm{H} \\
& \rightarrow{ }^{3} \mathrm{CH}_{2}+2 \mathrm{H} \\
& \rightarrow \mathrm{CH}+\mathrm{H}_{2}+2 \mathrm{H}
\end{aligned}
$$

In the premier analysis of methane conversion to ethane, the photochemical model of Yung et al. ${ }^{5}$ used a study of methane photodissociation by Slanger and Black ${ }^{17}$ in which the quantum yield of R2 and R3 at Lyman- $\alpha$ were given values of 0.41 and 0.51 , respectively, on the basis of their measurement of the $\mathrm{H}$ atom quantum yield from methane photolysis in conjunction with $\mathrm{H}_{2}$ measurements from Laufer and $\mathrm{McNesby}^{18}$ and the $\mathrm{CH}$ yield of 0.08 from Rebbert and Ausloos. ${ }^{19}$ The absence of a $\mathrm{CH}_{3}$ pathway made for a less efficient photolytic conversion of methane to ethane as the conversion scheme,

$$
\begin{aligned}
& \mathrm{CH}_{4}+h v \rightarrow{ }^{1} \mathrm{CH}_{2}+\mathrm{H}_{2} \\
& \mathrm{CH}_{4}+1 \mathrm{CH}_{2} \rightarrow \mathrm{CH}_{3}+\mathrm{CH}_{3} \\
& \mathrm{CH}_{3}+\mathrm{CH}_{3}+\mathrm{M} \rightarrow \mathrm{C}_{2} \mathrm{H}_{6}+\mathrm{M} \\
& \hline \mathrm{CH}_{4} \rightarrow \mathrm{C}_{2} \mathrm{H}_{6}+\mathrm{H}_{2}
\end{aligned}
$$

would be hindered by the quenching of methylene,

$$
{ }^{1} \mathrm{CH}_{2}+\mathrm{N}_{2} \rightarrow{ }^{3} \mathrm{CH}_{2}+\mathrm{N}_{2}
$$

because ground-state methylene $\left({ }^{3} \mathrm{CH}_{2}\right)$ promotes formation of unsaturated hydrocarbons at the expense of ethane.

The first direct measurement of the methyl radical $\left(\mathrm{CH}_{3}\right)$ through methane photolysis was conducted by Mordaunt et al., ${ }^{20}$ who observed methyl radicals accompanying "fast" $\mathrm{H}$ atoms through monitoring the kinetic energies of $\mathrm{H}$ photofragments via $\mathrm{H}$ atom translational spectroscopy. Through RRKM (Rice-Ramsperger-Kassel-Marcus) theory, they derived a methyl radical yield of $\sim 0.5$. Using a methane photolytic scheme based, in part, on this study, Wilson and
Atreya $^{15}$ concluded that a much more direct scheme was responsible for ethane production in the upper atmosphere.

$$
\begin{aligned}
& 2\left(\mathrm{CH}_{4}+h v \rightarrow \mathrm{CH}_{3}+\mathrm{H}\right) \\
& \frac{\mathrm{CH}_{3}+\mathrm{CH}_{3}+\mathrm{M} \rightarrow \mathrm{C}_{2} \mathrm{H}_{6}+\mathrm{M}}{2 \mathrm{CH}_{4} \rightarrow \mathrm{C}_{2} \mathrm{H}_{6}+2 \mathrm{H}}
\end{aligned}
$$

All recent studies of methane photolysis have derived a significant yield for the methyl pathway R1 while differing on the partitioning between R1 and R2. Although this discrepancy is rather negligible in determining the abundance of ethane, ${ }^{21}$ the determining scheme is relevant to the fate of $\mathrm{H}$ atoms. In scheme S2, H atoms are free to engage in further chemistry before undergoing escape, whereas scheme S1 locks the atoms in stable molecular form, destined to escape from the atmosphere without involvement in additional chemistry. We adopt the methane photolytic values ${ }^{22}$ of $0.29,0.58,0.0,0.07$, and 0.06 for the pathways $\mathrm{R} 1-\mathrm{R} 5$, respectively. This results in an ethane production rate of $8.3 \times 10^{7}$ molecules $\mathrm{cm}^{-2} \mathrm{~s}^{-1}$ referred to the surface, from S1 $+\mathrm{S} 2$, with the bulk of methane photolytic products going toward the production of unsaturated hydrocarbons and nitriles. In fact, the formation of unsaturated hydrocarbons and nitriles such as $\mathrm{C}_{2} \mathrm{H}_{4}$ and $\mathrm{HCN}$ is so efficient above $700 \mathrm{~km}$ that to form ethane from the recombination of methyl radicals, they have to be transported down to below $600 \mathrm{~km}$ (Figure 1), outside of the region where these processes are effective.

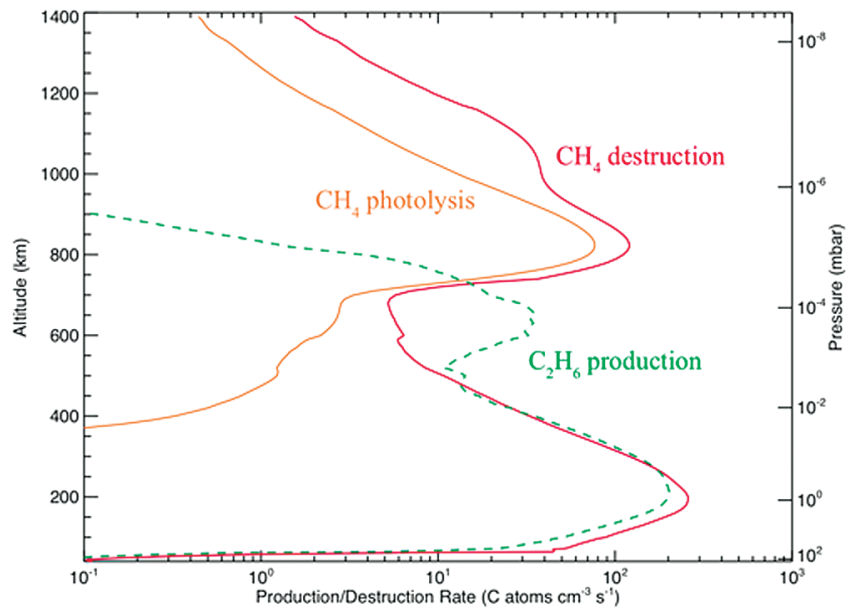

Figure 1. Red solid line is the chemical destruction rate profile for $\mathrm{CH}_{4}$, the orange solid line is the methane destruction rate profile due to photolysis, and the dashed line is the production rate profile for $\mathrm{C}_{2} \mathrm{H}_{6}$. 
Ethane can also be produced in the upper atmosphere through ion chemistry. This takes place not directly, but rather, through channels producing the methyl radical. However, the involvement of nitrogen atoms and ions, which serve to advance nitrile chemistry, makes this process less efficient in producing $\mathrm{C}_{2} \mathrm{H}_{6}$ molecules. Photodissociation and photoionization of methane and nitrogen molecules produce ethane molecules through the following mechanisms:

via $\mathrm{HCN}^{+}$

$$
\begin{gathered}
\quad\left(\begin{array}{l}
\mathrm{CH}_{4}+h v \rightarrow \mathrm{CH}_{3}+\mathrm{H} \\
\mathrm{N}_{2}+h v \rightarrow \mathrm{N}^{+}+\mathrm{N}(\mathrm{S} 4)+e^{-} \\
\mathrm{N}\left({ }^{4} \mathrm{~S}\right)+\mathrm{CH}_{3} \rightarrow \mathrm{H}_{2} \mathrm{CN}+\mathrm{H} \\
\mathrm{H}_{2} \mathrm{CN}+\mathrm{H} \rightarrow \mathrm{HCN}+\mathrm{H}_{2} \\
\mathrm{CH}_{4}+\mathrm{N}^{+} \rightarrow \mathrm{HCN}^{+}+\mathrm{H}_{2}+\mathrm{H} \\
\mathrm{CH}_{4}+\mathrm{HCN}^{+} \rightarrow \mathrm{H}_{2} \mathrm{CN}^{+}+\mathrm{CH}_{3} \\
\mathrm{H}_{2} \mathrm{CN}^{+}+e^{-} \rightarrow \mathrm{HCN}+\mathrm{H}
\end{array}\right) \\
6 \mathrm{CH}_{4} \frac{\mathrm{CH}_{3}+\mathrm{CH}_{3}+\mathrm{M} \rightarrow \mathrm{C}_{2} \mathrm{H}_{6}+\mathrm{M}}{+2 \mathrm{~N}_{2} \rightarrow 4 \mathrm{HCN}+\mathrm{C}_{2} \mathrm{H}_{6}+4 \mathrm{H}_{2}}+6 \mathrm{H}
\end{gathered}
$$

and via $\mathrm{CH}_{5}{ }^{+}$

$$
\begin{gathered}
2\left(\begin{array}{l}
2\left(\mathrm{CH}_{4}+h v \rightarrow \mathrm{CH}_{3}+\mathrm{H}\right) \\
\mathrm{N}_{2}+h v \rightarrow \mathrm{N}^{+}+\mathrm{N}(\mathrm{S} 4)+e^{-} \\
\mathrm{CH}_{4}+\mathrm{N}^{+} \rightarrow \mathrm{CH}_{4}^{+}+\mathrm{N}(\mathrm{S} 4) \\
2\left(\begin{array}{l}
\mathrm{N}\left({ }^{4} \mathrm{~S}\right)+\mathrm{CH}_{3} \rightarrow \mathrm{H}_{2} \mathrm{CN}+\mathrm{H} \\
\mathrm{H}_{2} \mathrm{CN}+\mathrm{H} \rightarrow \mathrm{HCN}+\mathrm{H}_{2}
\end{array}\right) \\
\mathrm{CH}_{4}+\mathrm{CH}_{4}^{+} \rightarrow \mathrm{CH}_{5}^{+}+\mathrm{CH}_{3} \\
\mathrm{C}_{2} \mathrm{H}_{4}+\mathrm{CH}_{5}^{+} \rightarrow \mathrm{C}_{2} \mathrm{H}_{5}^{+}+\mathrm{CH}_{4} \\
\mathrm{C}_{2} \mathrm{H}_{5}^{+}+e^{-} \rightarrow \mathrm{C}_{2} \mathrm{H}_{4}+\mathrm{H}
\end{array}\right) \\
6 \mathrm{CH}_{4} \frac{\mathrm{CH}_{3}+\mathrm{CH}_{3}+\mathrm{M} \rightarrow \mathrm{C}_{2} \mathrm{H}_{6}+\mathrm{M}}{+2 \mathrm{~N}_{2} \rightarrow 4 \mathrm{HCN}+\mathrm{C}_{2} \mathrm{H}_{6}+4 \mathrm{H}_{2}}+6 \mathrm{H}
\end{gathered}
$$

In both mechanisms, $2 / 3$ of the $\mathrm{C}$ atoms from methane go into the formation of $\mathrm{HCN}$, while only $1 / 3$ go into the production of ethane, highlighting their inefficiency in producing $\mathrm{C}_{2} \mathrm{H}_{6}$, as compared with $\mathrm{S} 1$ and $\mathrm{S} 2$. As a result, in the region where ion chemistry is most important, above $700 \mathrm{~km}$, only $2 \%$ of ethane formation is due to ion chemistry. Below this region, ion chemistry plays a negligible role in ethane production.

Below $700 \mathrm{~km}$, where methane destruction is at a minimum, methane is largely protected from direct photodissociation because the opacity provided by methane at higher altitudes prevents methane-dissociating photons from reaching the lower regions of the atmosphere. However, acetylene $\left(\mathrm{C}_{2} \mathrm{H}_{2}\right)$, produced in the middle and upper atmosphere from the photodissociation of ethylene $\left(\mathrm{C}_{2} \mathrm{H}_{4}\right)$, acts as a very efficient catalyst, sensitizing methane to photons of longer wavelength than those that can dissociate $\mathrm{CH}_{4}$ directly. Through the mechanism

$$
\begin{gathered}
\mathrm{C}_{2} \mathrm{H}_{2}+h v(\lambda>1450 \AA) \rightarrow \mathrm{C}_{2} \mathrm{H}+\mathrm{H} \\
\frac{\mathrm{C}_{2} \mathrm{H}+\mathrm{CH}_{4} \rightarrow \mathrm{C}_{2} \mathrm{H}_{2}+\mathrm{CH}_{3}}{\mathrm{CH}_{4} \rightarrow \mathrm{CH}_{3}+\mathrm{H}}
\end{gathered}
$$

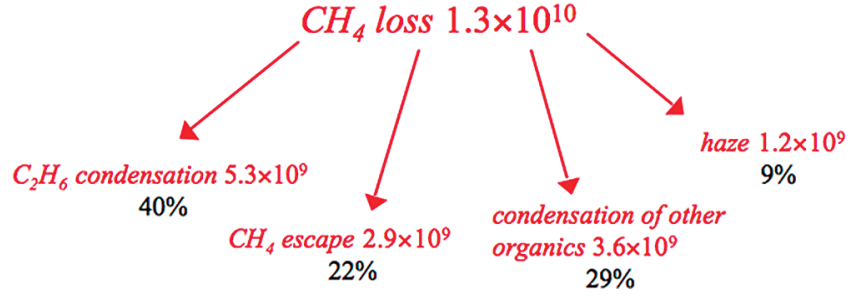

Figure 2. Pathways of methane loss in Titan's atmosphere. Values are integrated from $0-1400 \mathrm{~km}$.

methane is catalytically dissociated at a rate of $5.0 \times 10^{9}$ molecules $\mathrm{cm}^{-2} \mathrm{~s}^{-1}$ normalized to the surface, accounting for $46 \%$ of methane photochemical destruction. This chemical scheme peaks in the stratosphere (Figure 1), providing for a source of ethane production aided by the larger atmospheric density of the lower atmosphere.

$$
\begin{gathered}
\mathrm{C}_{2} \mathrm{H}_{2}+h v \rightarrow \mathrm{C}_{2} \mathrm{H}+\mathrm{H} \\
\mathrm{C}_{2} \mathrm{H}+\mathrm{CH}_{4} \rightarrow \mathrm{C}_{2} \mathrm{H}_{2}+\mathrm{CH}_{3} \\
\frac{\mathrm{CH}_{3}+\mathrm{CH}_{3}+\mathrm{M} \rightarrow \mathrm{C}_{2} \mathrm{H}_{6}+\mathrm{M}}{2 \mathrm{CH}_{4} \rightarrow \mathrm{C}_{2} \mathrm{H}_{6}+2 \mathrm{H}}
\end{gathered}
$$

Ninety-seven percent of ethane production takes place below $700 \mathrm{~km}$, chiefly through acetylenic catalysis. This photosensitized dissociation also occurs through $\mathrm{HCN}, \mathrm{HC}_{3} \mathrm{~N}$, and $\mathrm{C}_{4} \mathrm{H}_{2}$, but on a lesser scale, accounting for an ethane production rate an order of magnitude smaller than through $\mathrm{C}_{2} \mathrm{H}_{2}$. Apart from this catalytic dissociation of methane and the photodissociation schemes of $\mathrm{S} 1$ and $\mathrm{S} 2$, the balance of $\mathrm{CH}_{4}$ destruction proceeds through the formation of ethylene $\left(\mathrm{C}_{2} \mathrm{H}_{4}\right)$, via the $\mathrm{CH}$ and ${ }^{3} \mathrm{CH}_{2}$ radicals and through ion-molecule reactions above $700 \mathrm{~km}$, which help populate Titan's upper ionosphere.

Early estimates of ethane condensation from methane conversion $^{7}$ assumed that the large bulk of methane loss goes toward the eventual deposition of $\mathrm{C}_{2} \mathrm{H}_{6}$ onto Titan's surface. Although this conversion from methane to ethane is quite efficient over a large range of altitudes in Titan's atmosphere, it is not the only mechanism pertaining to methane loss. Recent analysis of the energetics of Titan's upper atmosphere from Cassini-Huygens observations reveals ${ }^{23}$ a methane loss rate of $2.9 \times 10^{9}$ molecules $\mathrm{cm}^{-2} \mathrm{~s}^{-1}$ due to hydrodynamic escape, evident from heating rates obtained by the Huygens Atmospheric Structure Instrument (HASI) on the Huygens probe. ${ }^{24}$ This loss rate would correspond to $22 \%$ of the total methane loss rate (Figure 2). Methane photochemistry also leads to the formation of a bevy of hydrocarbons and nitriles that make up Titan's inventory of tracers, many of which condense out to the surface. Some of these compounds are polymerized and are engaged in chemical reactions that promote molecular growth, eventually resulting in the formation of Titan haze. Model results show that $1.2 \times 10^{9} \mathrm{C}$ atoms $\mathrm{cm}^{-2} \mathrm{~s}^{-1}$ or $2.4 \times 10^{-14} \mathrm{~g} \mathrm{~cm}^{-2} \mathrm{~s}^{-1}$ from methane destruction goes into reactions that lead to Titan haze. Another $29 \%$ of methane loss results in the formation of condensates of hydrocarbons and nitriles (Figure 2).

Ethane as a closed-shell molecule is very stable, but it does participate in reactions that ultimately extend the growth of alkane and alkene molecules. These reactions take place primarily with halogen-like radicals (e.g., $\mathrm{C}_{2} \mathrm{H}, \mathrm{CN}$ ) in hydrogen abstraction type reactions (Figure 3). In the upper atmosphere, the availability of $\mathrm{CH}$ radicals originating from the photolysis 


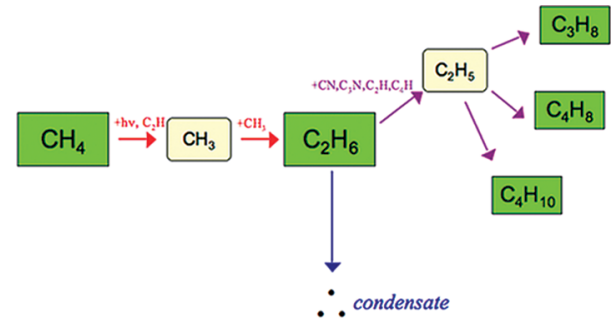

Figure 3. Production and loss pathways for ethane in Titan's atmosphere.

of methane provides the primary loss process for ethane above $700 \mathrm{~km}$, promoting the formation of propylene.

$$
\begin{gathered}
\mathrm{CH}_{4}+h v \rightarrow \mathrm{CH}+\mathrm{H}_{2}+\mathrm{H} \\
\frac{\mathrm{C}_{2} \mathrm{H}_{6}+\mathrm{CH} \rightarrow \mathrm{C}_{3} \mathrm{H}_{6}+\mathrm{H}}{\mathrm{CH}_{4}+\mathrm{C}_{2} \mathrm{H}_{6} \rightarrow \mathrm{C}_{3} \mathrm{H}_{6}+\mathrm{H}_{2}+\mathrm{H}}
\end{gathered}
$$

In the lower atmosphere, ethyl radicals are made available through hydrogen abstraction of ethane

$$
\begin{array}{r}
\mathrm{C}_{2} \mathrm{H}_{6}+\left(\mathrm{C}_{2} \mathrm{H}, \mathrm{C}_{4} \mathrm{H}, \mathrm{CN}, \mathrm{C}_{3} \mathrm{~N}\right) \rightarrow \mathrm{C}_{2} \mathrm{H}_{5}+ \\
\left(\mathrm{C}_{2} \mathrm{H}_{2}, \mathrm{C}_{4} \mathrm{H}_{2}, \mathrm{HCN}, \mathrm{HC}_{3} \mathrm{~N}\right)
\end{array}
$$

which leads to higher-order hydrocarbons through pressuredependent radical-radical addition reactions:

$$
\begin{gathered}
\mathrm{C}_{2} \mathrm{H}_{5}+\mathrm{CH}_{3}+\mathrm{M} \rightarrow \mathrm{C}_{3} \mathrm{H}_{8}+\mathrm{M} \\
\mathrm{C}_{2} \mathrm{H}_{5}+\mathrm{C}_{2} \mathrm{H}_{3}+\mathrm{M} \rightarrow \mathrm{C}_{4} \mathrm{H}_{8}+\mathrm{M} \\
\mathrm{C}_{2} \mathrm{H}_{5}+\mathrm{C}_{2} \mathrm{H}_{5}+\mathrm{M} \rightarrow \mathrm{C}_{4} \mathrm{H}_{10}+\mathrm{M}
\end{gathered}
$$

R7 destroys ethane at a rate of $4.3 \times 10^{8}$ molecules $\mathrm{cm}^{-2} \mathrm{~s}^{-1}$, amounting to $15 \%$ of the production rate of $\mathrm{C}_{2} \mathrm{H}_{6}$. Meanwhile, the most important of these addition reactions is $\mathrm{R} 8$, which leads to the formation of propane $\left(\mathrm{C}_{3} \mathrm{H}_{8}\right)$. Although model calculations predict a mole fraction for $\mathrm{C}_{3} \mathrm{H}_{8}$ three times greater than observations in the lower stratosphere (Figure $4 \mathrm{a}$ ) obtained by the composite infrared spectrometer (CIRS), ${ }^{25}$ this discrepancy does not significantly impact the calculated ethane condensation fluxes, because condensation rather than chemical loss to propane is the primary loss process for $\mathrm{C}_{2} \mathrm{H}_{6}$. For instance, reducing the rate coefficient for $\mathrm{R} 8$ by a factor of 3 would put the $\mathrm{C}_{3} \mathrm{H}_{8}$ profile in line with observations while only increasing the ethane condensation flux by $10 \%$. Our understanding of the conversion from ethane to higher-order hydrocarbons would be aided by additional study of these pressure-dependent addition reactions, which have not been examined under conditions representative of Titan's atmosphere.

Ethane is also photolyzed shortward of $1600 \AA$, but the shielding provided by methane molecules protects $\mathrm{C}_{2} \mathrm{H}_{6}$ from significant photodestruction, so that only $3.5 \times 10^{7}$ molecules $\mathrm{cm}^{-2} \mathrm{~s}^{-1}$ are lost in this manner.

\section{Ethane Condensation}

Because the destruction of ethane molecules cannot keep pace with its efficient production in Titan's stratosphere, a significant amount of ethane is diffused upward through eddy mixing. In one-dimensional photochemical models, this process is simulated through the eddy diffusion parameter. In the case of Titan's atmosphere, the ethane profile serves as a good candidate for testing the accuracy of an eddy diffusion profile, given its stability and relatively simple chemistry. Adopting an eddy diffusion profile with a homopause at $1050 \mathrm{~km}$ to match $\mathrm{CH}_{4}$ observations obtained by the ion and neutral mass spectrometer (INMS) instrument ${ }^{26}$ on the Cassini spacecraft produces profiles for $\mathrm{CH}_{4}$ and $\mathrm{C}_{2} \mathrm{H}_{6}$ (Figure 4a) that match well with the INMS observations in the upper atmosphere ${ }^{24}$ and CIRS observations in the lower atmosphere. ${ }^{27}$ With this in mind, a value for ethane loss due to condensation can be confidently obtained.

The present model yields an ethane condensation rate $(2.7$ $\times 10^{9}$ molecules $\mathrm{cm}^{-2} \mathrm{~s}^{-1}$ ) that is similar to the values in recent studies, ${ }^{11,16}$ all referenced to the surface of Titan, and roughly $45 \%$ of that calculated in the first model on ethane condensation $\left(5.8 \times 10^{9}\right.$ molecules $\left.\mathrm{cm}^{-2} \mathrm{~s}^{-1}\right) .^{5}$ The Yung et al. model was the basis for the prediction of a kilometer-deep global ocean of ethane on Titan. ${ }^{7}$ Thus, even after unprecedented data on the composition of Titan's atmosphere and great advances in our understanding of the atmospheric carbon budget as detailed in this paper, the current photochemical model still allows for an accumulation of an approximately 400-m-deep layer of ethane liquid on Titan's surface over geologic time. However, several factors would tend to reduce the depth of such a layer.

Models indicate that the outgassing of methane from Titan's interior may occur only episodically, with the last such episode some 600 Myr ago. ${ }^{28}$ This would imply a reduction in the depth of the ethane layer down to approximately $50 \mathrm{~m}$. This assumes, of course, the methane abundance we see on Titan today has been constant throughout this period. Considering the 30-100 million year photochemical lifetime of methane on Titan, this assumption is far from justified. In the best case scenario of a 100 Myr lifetime, the amount of methane-hence, the accumulation rate of the ethane liquid-would gradually decline over this period to $2.5 \times 10^{-3}$ of the starting value at the last episode of methane outgassing (note the starting mole fraction of methane is unlikely to exceed much more than twice the present day value of $5 \%$ by volume, which is at roughly $50 \%$ relative humidity). This would suggest a $1 \mathrm{~m}$ depth of ethane liquid on the surface. However, this scenario of the exponential decline in methane abundance since the last episodic event would also mean that essentially no methane would be present on Titan today, contrary to observations. This presence of methane, thus, suggests that either the last episodic release of methane was more recent, or that small amounts of methane are released more frequently due to impact or cryovolcanism. While preventing complete depletion of methane from the atmosphere, such a scenario would result in some of the methane released into the troposphere finding its way into the stratosphere, where it could be photochemically converted to ethane and other products, resulting in additional ethane condensation beyond the aforementioned $1 \mathrm{~m}$ estimate. Thus, we surmise that the depth of the ethane liquid could approach about $10 \mathrm{~m}$ as a result of these processes. A $10 \mathrm{~m}$ depth of ethane liquid would yield an inventory of $8.3 \times 10^{5} \mathrm{~km}^{3}$ as compared to RADAR Titan observations $^{29}$ that suggest a liquid inventory of $3 \times 10^{4}$ to 3 $\times 10^{5} \mathrm{~km}^{3}$.

Ethane liquid may also get sequestered as clathrate in Titan's regolith. ${ }^{12}$ Mousis and Schmitt ${ }^{30}$ estimate that a cryovolcanic icy crust less than $2.3 \mathrm{~km}$ thick is required to bury all the ethane (and other less abundant hydrocarbon liquids) produced over geologic time. If the methane were recent (i.e., since the last episode $600 \mathrm{Myr}$ ago), the icy crust would need to be only tens 

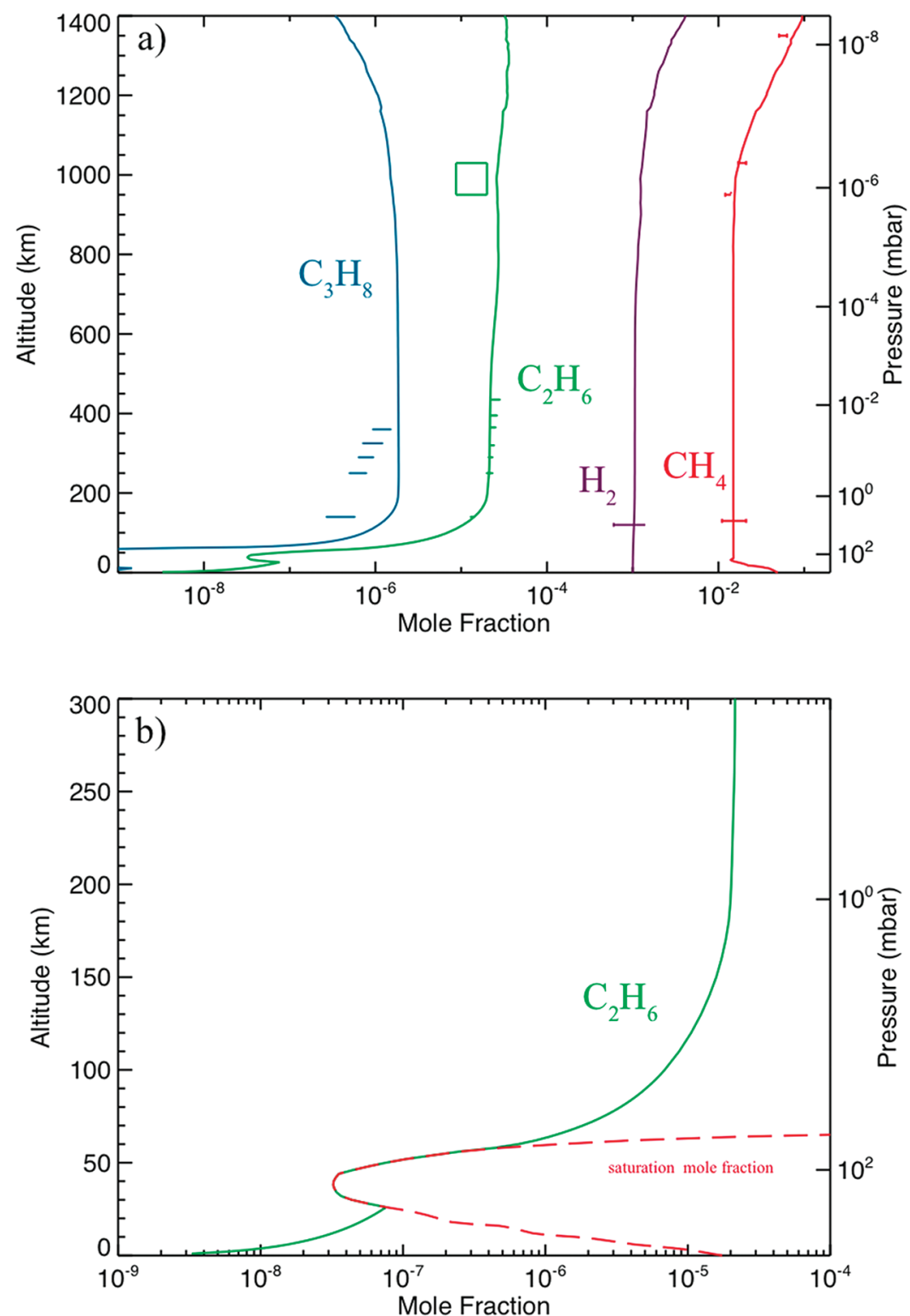

Figure 4. (a) Model profiles for saturated hydrocarbons and $\mathrm{H}_{2}$ in Titan's atmosphere with Cassini observations for the lower atmosphere ${ }^{26}$ and upper atmosphere, and Voyager $\mathrm{H}_{2}$ observations. ${ }^{34}$ (b) The model-generated mole fraction profile (solid line) and the saturation mole fraction profile (dashed line) for $\mathrm{C}_{2} \mathrm{H}_{6}$.

of meters thick to bury the ethane liquid. From time to time, the ethane (together with other volatiles) would be released to the surface when the clathrates are destabilized, resulting in liquids at the surface.

Despite the lack of global oceans of ethane on Titan, envisioned in earlier studies, ethane liquid is expected on the surface, in the form of pools or lakes. Ethane is fully miscible in liquid methane so that bodies of liquid on Titan are expected to be a mixture of methane and ethane, along with smaller concentrations of other hydrocarbons, such as propane, butane, and benzene, as well as certain nitriles. The VIMS spectroscopic identification of ethane in Ontario Lacus located at a southern polar latitude $^{15}$ is a confirmation of ethane as a component of at least one polar lake on Titan. (The large abundance of methane gas in the atmosphere has prevented the identification of methane liquid by VIMS.) As observations over more lakes are carried out in the Cassini extended mission, spectroscopic identification of ethane liquid may be possible in other lakes as well. Furthermore, spectra from the VIMS instrument have revealed the presence of a tropospheric cloud likely composed of ethane in the northern high latitudes. ${ }^{31}$ The Huygens gas chromatograph/mass spectrometer found evidence of a moist surface, with ethane (among other volatiles) evaporating from the surface heated by the warm underbelly of the probe. ${ }^{8}$ Since Huygens landed on Titan in a dry season in the equatorial region, no large bodies of liquids were present at that time. On the other hand, temperatures only a few degrees colder, such as those prevalent at the polar latitudes, are sufficient for greater condensation of ethane (and methane) on Titan. ${ }^{11}$

The estimate of the actual amount of ethane liquid in the lakes is complicated due to several factors, including survival of the ethane droplets as they descend through the atmosphere and after they land on the surface. Not only do thermodynamics of the ternary mixture of $\mathrm{CH}_{4}-\mathrm{N}_{2}-\mathrm{C}_{2} \mathrm{H}_{6}$ play a role in the stability of ethane droplets against evaporation, ${ }^{32}$ there also is a good likelihood of the processing of surface material over time. Such processing could occur due to the action of charged particles or communication between the interior and the surface. Although a vast majority of the galactic cosmic rays (GCR) are stopped above the tropopause of Titan, a small flux of 
relatively high energy GCR is expected to reach the surface. The charged particle-induced chemistry, either directly by the GCR or by the secondary electrons produced as the GCR slow down in their interaction with the atmosphere and the surface material, would alter the composition of the surface. Although GCR have not been directly monitored in Titan's atmosphere, measurements of the electrical conductivity in the lower atmosphere conducted by the Huygens probe ${ }^{33}$ indicate their existence in Titan's stratosphere. Furthermore, GCR can play a substantial role in the formation of certain nitriles. ${ }^{16}$ Observations of these nitriles in the stratosphere by CIRS and on the surface by GC/MS can provide a proxy for the penetration of galactic cosmic rays into the lower atmosphere and their influence on surface material. Material released from the interior in cryovolcanic processes, especially water, ammonia, and other volatiles from Titan's interior ocean, may also chemically interact with the surface liquids and modify them. Although all the above surface-altering chemical processes are likely to be relatively slow, time is not a major factor, because once the atmospheric products are on the surface, they can remain undisturbed under Titan's environmental conditions unless processed by such processes as the GCR, interior material, or impacts. When that happens, ethane (and other volatiles) would transform into other forms, thus reducing their abundance in the surface and the lakes, since the reverse process of recycling in such an environment is highly unlikely.

\section{Conclusions}

The process of methane photochemistry resulting in ethane condensation has been analyzed with updated photochemistry. It has been shown that methane destruction, contrary to previous predictions, has a much more heterogeneous suite of end products, and $40 \%$ of the total methane loss rate does result in ethane production. Upper atmospheric processes such as the prominent photodissociation of methane and ion chemistry are not the main catalyst, but rather, photosensitized dissociation in Titan's stratosphere, with acetylene acting as the main catalyst. This process acts as a major source of free hydrogen atoms, which play a prominent role in hydrocarbon growth through pressure-induced $\mathrm{H}$-addition chain reactions in Titan's stratosphere. ${ }^{16}$ Other condensates and haze account for $38 \%$ of methane loss, with $22 \%$ due to escape. These processes would result in a liquid ethane layer of $400 \mathrm{~m}$ on Titan's surface over geologic time, but this layer could be reduced to levels indicated today by episodic outgassing of methane, thermodynamics, and the chemical processing of surface material. Understanding how these processes proceed in Titan's troposphere and surface will reveal the nature of Titan's surface and the factors responsible for its makeup today.

\section{References and Notes}

(1) Strobel, D. F. Icarus 1974, 21, 466-470.

(2) (a) Gillet, F. C.; Forrest, W.; Merrill, K. M. Astrophys. J. 1973, 184, L93-L95. (b) Danielson, R. E.; Caldwell, J. J.; Larach, D. R. Icarus 1973, 20, 437-443. (c) Gillet, F. C. Astrophys. J. 1975, 187, L37-L38.

(3) (a) Hanel, R. Science 1981, 212, 192-200. (b) Coustenis, A.; Bézard, B.; Gautier, D. Icarus 1989, 80, 54-76. (c) Coustenis, A.; Bézard, B.; Gautier, D.; Marten, A. Icarus 1991, 89, 152-167.

(4) Allen, M.; Pinto, J. P.; Yung, Y. L. Astrophys. J. 1980, 242, L125L128.

(5) Yung, Y. L.; Allen, M.; Pinto, J. P. Astrophys. J. Suppl. 1984, 55, $465-506$.

(6) Lindal, G. F.; Wood, G. E.; Hotz, H. B.; Sweetnam, D. N.; Eshleman, V. R.; Tyler, G. L. Icarus 1983, 53, 348-363.

(7) Lunine, J. L.; Stevenson, D. J.; Yung, Y. L. Science 1983, 222, $1229-1230$.

(8) Niemann, H. B.; , et al. Nature 2005, 438, 779-784.

(9) (a) Sotin, C. Nature 2005, 435, 786-789. (b) Barnes, J. W. Geophys. Res. Lett. 2006, 33, L16204.

(10) (a) Elachi, C. Science 2005, 308, 970-974. (b) Lopes, R. M. C. Icarus 2007, 186, 395-412.

(11) Atreya, S. K.; Adams, E. Y.; Niemann, H. B.; Demick-Montelara, J. E.; Owen, T.; Fulchignoni, M.; Ferri, F.; Wilson, E. H. Planet. Space Sci. 2006, 54, 1177-1187.

(12) Lunine, J. I.; Atreya, S. K. Nature Geosci. 2008, 1, 159-164.

(13) McCord, T. B. Planet. Space Sci. 2006, 54, 1524-1539.

(14) Stofan, E. R. Nature 2007, 445, 61-64.

(15) Brown, R. H.; Soderblom, L. A.; Soderblom, J. M.; Clark, R. N.; Jaumann, R.; Barnes, J. W.; Sotin, C.; Buratti, B.; Baines, K. H.; Nicholson, P. D. Nature 2008, 454, 607-610.

(16) Wilson, E. H.; Atreya, S. K. J. Geophys. Res. 2004, 109, E06002, doi:10.1029/2003JE002181.

(17) Slanger, T. G.; Black, G. J. Chem. Phys. 1982, 77, 2432-2437.

(18) Laufer, A. H.; McNesby, J. R. J. Chem. Phys. 1968, 49, 22722278.

(19) Rebbert, R. E.; Ausloos, P. J. Photochem. 1972/1973, 1, 171-176.

(20) Mordaunt, D. H.; Lambert, I. R.; Morley, G. P.; Ashfold, N. R.; Dixon, R. N.; Western, C. M.; Schnieder, L.; Welge, K. H. J. Chem. Phys. 1993, 98, 2054-2065.

(21) Wilson, E. H.; Atreya, S. K. J. Geophys. Res. 2000, 105, 2026320273.

(22) Hamelin, M. Planet. Space Sci. 2007, 1964-1977.

(23) Wang, J.- H.; Liu, K.; Min, Z.; Su, H.; Bersohn, R.; Preses, J.;

Larese, Z. J. Chem. Phys. 2000, 113, 4146-4152.

(24) Strobel, D. F. Icarus 2008, 193, 588-594

(25) Fulchignoni, M. Nature 2005, 438, 785-791.

(26) Vinatier, S. Icarus 2007, 188, 120-138.

(27) (a) Waite, J. H. Science 2005, 308, 982-986. (b) Waite, J. H.;

Young, D. T.; Cravens, T. E.; Coates, A. J.; Crary, F. J.; Magee, B.; Westlake, J. Science 2007, 316, 870-875.

(28) (a) Flasar, F. M. Science 2005, 308, 975-975. (b) Vinatier, S.; Bézard, B.; Fouchet, T.; Teanby, N. A.; de Kok, R.; Irwin, P. G. J.; Conrath, B. J.; Nixon, C. A.; Romani, P. N.; Flasar, F. M.; Coustenis, A. Icarus 2007, 188, 120-138.

(29) Tobie, G.; Lunine, J. I.; Sotin, C. Nature 2006, 440, 61-64.

(30) Lorenz, R. D. Geophys. Res. Lett. 2008, 35, L02206, doi:10.1029/ 2007GL032118.

(31) Mousis, O.; Schmitt, B. Astrophys. J. 2008, 677, L67-L70.

(32) Griffith, C. A. Science 2006, 313, 1620-1622.

(33) Graves, S. D.; McKay, C. P.; Griffith, C. A.; Ferri, F. Planet. Space Sci. 2008, 56, 346-357.

(34) Courtin, R. D.; Gautier, D.; McKay, C. P. Icarus 1995, 114, $144-162$.

JP905535A 